\title{
Multi-scale features including water content of polymer induced kaolinite floc structures
}

\author{
Sugandha Sharma, Chen-Luh Lin, *Jan D. Miller \\ Department of Metallurgical Engineering \\ College of Mines and Earth Sciences \\ University of Utah \\ 135 South 1460 East Room 412 \\ Salt Lake City, UT 84112-0114, USA \\ Sugandha.ismdhanbad@gmail.com (S. Sharma) \\ Chenluh.lin@utah.edu (C.L. Lin) \\ *Jan.miller@utah.edu (J.D. Miller, Corresponding Author) \\ Phone: +1-801-581-5160 \\ Fax: +1-801-581-4937
}

\begin{abstract}
Despite their many uses, fine clay particles, such as kaolinite, present a problem in the management of tailings in various mineral industries such as the oil sands and phosphate processing industries. The effective flocculation, sedimentation and consolidation of these fine particles are major challenges. The structure of the flocs and the water entrapped within the flocs determine floc behavior and settling characteristics. The quantification of water entrapped within the kaolinite flocs has not been reported previously.

In this research, a new technique was developed for water content and size analysis of sedimented kaolinite flocs using High Resolution X-ray Microtomography (HRXMT). The results suggest a normal distribution of water content for these flocs, with mean water content of 53.9\% by volume and a standard deviation of $11.8 \%$. About $98 \%$ of the flocs were found to have water content in the range $30-80 \%$. The size analysis revealed that about $90 \%$ of the flocs are less than $1.5 \mathrm{~mm}$ in size. The water content was found to decrease with an increase in size of the floc. The floc shape analysis was done for selected flocs. The flocs were found to be fairly irregular, with sphericity values around 0.1 .

In addition to macroscopic analysis of individual flocs, flocs were also analyzed for their microstructure by cryo-SEM. Visualization of floc microstructure and polymer chains revealed the stabilization of kaolinite microflocs in the web formed by polymer chains. The structure of the polymer chains as well as the interaction between microflocs and polymer chains is a key to understanding floc growth and stability.
\end{abstract}

Key words: Kaolinite, Polyacrylamide, Flocculation, Sedimentation, X-ray Tomography, Floc size, Floc shape, Floc water content, Scanning electron microscopy, Floc microstructure 


\section{Contents}

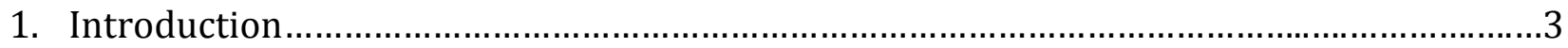

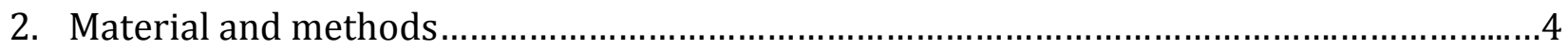

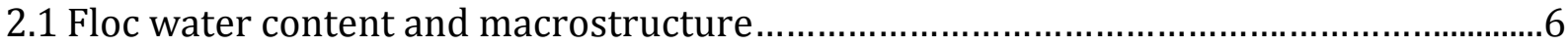

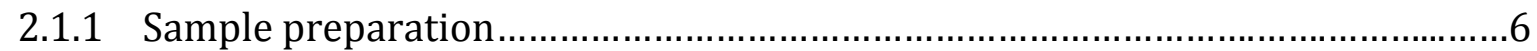

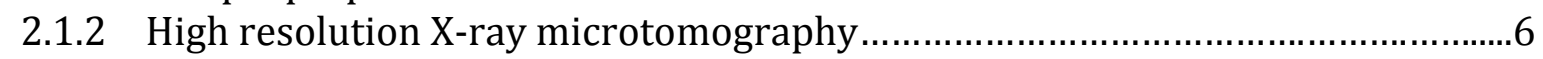

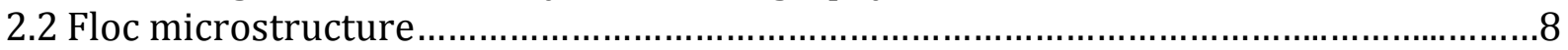

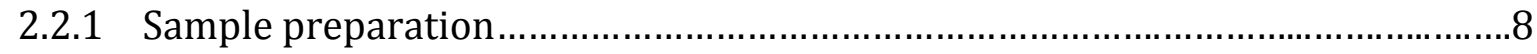

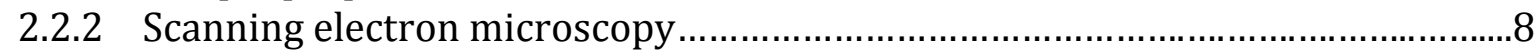

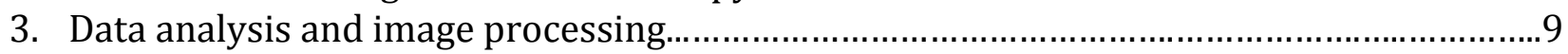

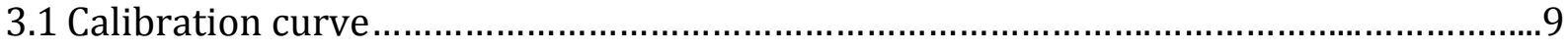

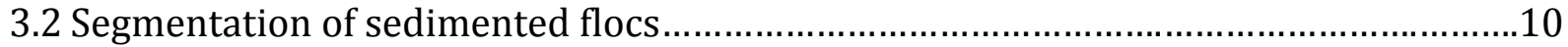

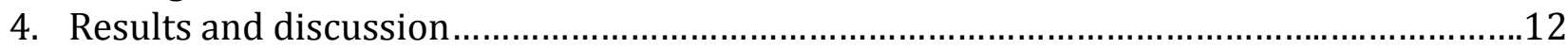

4.1 Floc water content and macrostructure............................................................... 12

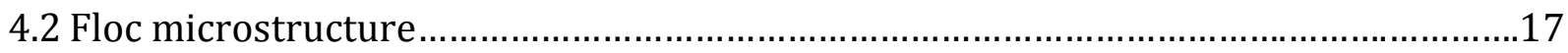

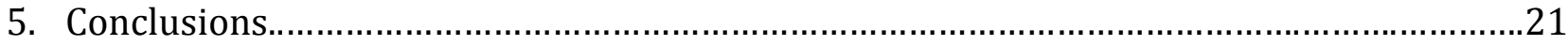

Acknowledgements

References 


\section{Introduction}

Fine clays, such as kaolinite, pose a huge challenge for the management of tailings in various mineral industries such as the oil sands and phosphate processing industries (Zhang \& Bogan, 1995; Chalaturnyk et al., 2002). The surface charge characterization of kaolinite clay using Atomic Force Microscopy (AFM) has been reported previously (Gupta \& Miller, 2010; Liu et al., 2014). They concluded that at low $\mathrm{pH}$ values (below $\mathrm{pH}$ 6.5), the alumina face is positively charged while the silica face and edge surface are negatively charged. However, all three surfaces (alumina face, silica face and edge surface) are negatively charged at higher $\mathrm{pH}$ values. The presence of oppositely charged surfaces at low $\mathrm{pH}$ values promotes aggregation between these fine clay particles leading to the formation of kaolinite clusters. These kaolinite particles become associated with edge-to-edge, edge-to-face or face-to-face interactions giving rise to a card-house type structure as suggested in the literature (Kie, 1954; Van Olphen, 1977). The card-house structure of kaolinite clusters has been discussed by various researchers over the past years and has recently been described using a dynamic coarse grain simulation model (Liu et. al., 2015).

These clusters are about $10 \mu \mathrm{m}$ in size, however, further increase in the size of aggregates can be obtained by the addition of coagulants or flocculants or both. Polyacrylamide based polymers (PAMs) are generally used as flocculants for tailings containing kaolinite and other fine clays. As the flocs settle under gravity, they form a sediment bed which contains a network of interconnected flocs and water channels. Further consolidation of the sediment is required to release the water for recycling and to minimize the sediment volume for land reclamation. The characterization of floc size, shape and entrapped water content will be helpful in understanding and influencing the tailings settling rate, sedimentation and consolidation.

Influencing the size, mass, surface area, and number concentration of particles substantially affects their removal by gravity sedimentation and deposition in packed-bed filters (Lawler, 1986; O'Melia, 1998). In addition to size, particle shape affects the behavior of aggregated particles, particularly with regard to collision efficiency (Jiang \& Logan, 1991; Wiesner, 1992) and settling rates (Johnson et al., 1996; Li \& Logan, 1997; Chakraborti et al., 2000). The particle size and solids weight percentage in the slimes determine the settling characteristics and amount of flocculant required to settle the slimes. The amount of water contained in flocs is directly influenced by the size of the flocs (Winterwerp \& van Kesteren, 2004) and the rate at which flocculation occurs (Mietta, 2010). The water content of the flocs also influences the settling and self-weight consolidation (Hendricks, 2016). Previously, techniques such as Nuclear Magnetic Resonance (NMR) spectroscopy have been used to study the water content in different clays (Fan et al., 1999). The analysis of water content for individual kaolinite flocs is yet to be reported. The intra-floc water and size/shape analysis of flocs in kaolinite sediment is challenging due to the problems in imaging and segmentation of the sediment into individual flocs.

The use of X-ray microtomography (XMT) in mineral processing applications has increased over the past few years. Its use has been extended to include size, shape, texture, exposure and liberation of multiphase mineral particle populations (Garcia et al., 2009; Lin \& Miller, 2005, 2010). More recently, High Resolution X-ray Microtomography (HRXMT) has been used for 3D particle characterization, multiphase particle segmentation, and data analysis at the University of Utah (Lin et al., 2010; Wang et al., 2015). HRXMT, along with image processing and visualization tools such as ImageJ (Schindelin et al., 2012), Medical Image Processing Analysis \& Visualization (MIPAV) (McAuliffe et al., 2001) and Drishti (Limaye, 2012), are powerful tools for particle segmentation and structure analysis. 
Although HRXMT has been used previously for studying multiphase solid particles, it has never been used for studying the structure and water content of individual flocs in a sediment bed. In this research, water content and size analysis of kaolinite flocs has been accomplished by using HRXMT and various in-house developed techniques. The kaolinite floc sediment bed was treated as a two phase system containing water and kaolinite and the principles of multiphase particle segmentation were applied to the sediment bed to isolate and identify individual flocs.

In addition to the macro scale characterization of flocs, the investigation of floc microstructure is also reported in this work. The flocs are formed by various mechanisms on addition of polymer to the kaolinite suspension. Visualization of floc microstructure would help us understand the interaction between the polymer chains and the kaolinite particles which eventually influence the floc size and shape. In the past, various aspects of kaolinite floc structure and rheological properties have been studied in detail using Scanning Electron Microscopy (SEM) (Mpofu, et al., 2003; Kim \& Palomino, 2009; Zbik et al., 2008; Du et. al., 2009). The results from all these studies are interesting and give information about floc structure during different stages of sedimentation (Zbik et al., 2008), the effect of polymer concentration (Kim \& Palomino, 2009), and the effect of polymer type (Mpofu et al., 2003; Kim \& Palomino, 2009). Most of these studies focus on the type of primary particle interactions, i.e. edge-edge, edge-face, face-face interactions at different conditions. Kim \& Palomino (2009) concluded that with an increase in polymer concentration face-face interactions increase resulting in higher density of flocs. They also investigated the effect of polymer type and concluded that cationic polymers produce more porous flocs than the anionic polymer induced flocs. Mpofu's research suggests that free settling flocs show predominant edge-edge interaction whereas settled flocs show more face-face interaction (Mpofu et al., 2003). Although we have some idea about the structure of kaolinite clusters, we have limited information on the structure of polymer chains and how these chains bridge the smaller aggregates and create flocs millimeters in size. In this research, an attempt has been made using SEM to visualize the kaolinite floc microstructure as well as polymer bridges connecting these microstructures. Such visualization will enhance our understanding of kaolinite floc formation with a polyacrylamide flocculant. This information can, in turn, help in selection of appropriate polymers and operating conditions for flocculation.

\section{Materials and methods}

Acid washed K2 500 kaolinite (U.S.) obtained from Fisher Scientific was used in this study. The size analysis of primary particles was done using Dynamic Light Scattering (DLS) manufactured by Wyatt Technologies. DLS utilizes time-dependent fluctuations of scattered intensity, which arise from Brownian motion, in order to determine the diffusion constant. The hydrodynamic radius $R_{\mathrm{h}}$ is then calculated directly as described in the DLS theory. Details about the DLS theory and other working principles are described in the literature (Berne \& Pecora, 2000). Kaolinite suspensions at pH 8.6 containing $0.1 \%$ solids were used in this research. About $1 \mathrm{ml}$ of suspension was put in a cuvette and the system was sonicated for about 10 seconds. The cuvette was then inserted into the DLS system and the size analysis was done. Two peaks were observed during the analysis, at about $100 \mathrm{~nm}$ and at $600 \mathrm{~nm}$ (Figure 1). The analysis suggests a bimodal size distribution of kaolinite primary particles. 


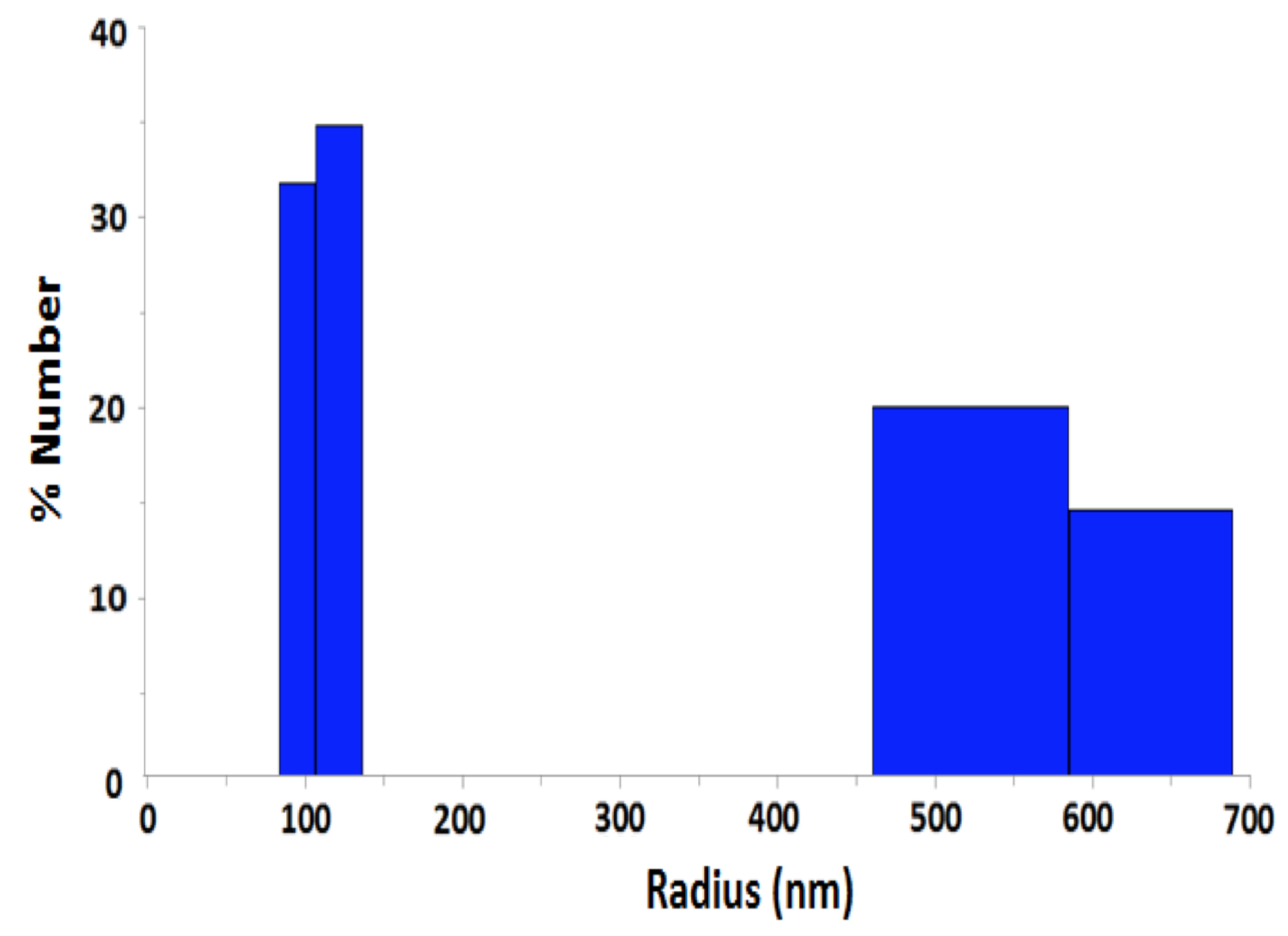

Figure 1: Size analysis of kaolinite primary particles using DLS. A kaolinite suspension at $\mathrm{pH} 8.6$ and solid concentration $0.1 \%$ was analyzed.

Polyacrylamide based polymer (AF 303) was obtained from Hychem Inc. The polyacrylamide monomer contains two functional groups, the acryl and the amide group. The extent of substitution of these groups determines the charge density. The polymer used has molecular weight in the range of 12-14 million and a negative charge density of 5\%. The polymer selection and solution preparation was done based on recommendations from Pocock Industrial, Salt Lake City, Utah. The polymer was added to suspensions in an aqueous solution state at 0.1 $\mathrm{g} / \mathrm{l}$ concentration. The solid polymer particles in powder form were added to DI water and a stock solution with a polymer concentration of $1 \mathrm{~g} / \mathrm{l}$ was prepared. The solution was allowed to equilibrate while being stirred for 8 hours at $400 \mathrm{rpm}$. Right before addition to the kaolinite suspension, some of the polymer solution was diluted to $0.1 \mathrm{~g} / \mathrm{l}$ and then added to the suspension. Fresh stock solution was prepared every five days as the polymer solution showed some aging if stored for a longer period of time. The aging was evident by a change in viscosity and/or a change in color to off-white. The stock solution was always refrigerated and stored at lower temperatures. 


\subsection{Floc water content and macrostructure}

\subsubsection{Sample preparation}

Pure water and kaolinite were prepared at different solids content by weight and scanned for calibration. About $50 \mathrm{ml}$ of kaolinite paste with $80 \%$ solids content by weight was prepared. A portion of the paste was transferred to a $20 \mathrm{ml}$ test tube and was allowed to equilibrate for about 6 hours. It was scanned using the HRXMT and the scaled CT number was found. The process was repeated for four different solids concentrations. Using the scaled CT numbers, a calibration curve was plotted showing the variation in scaled CT number with water content (Lin et al., 2010).

The sedimented kaolinite flocs were prepared from a 5\% w/v kaolinite suspension. The sample was allowed to stir for 1 hour at $400 \mathrm{rpm}$ and sonicated for 20 minutes. The $\mathrm{pH}$ of the suspension was noted to be 5.8. High mol. wt. 5\% anionic polymer was added to the suspension drop by drop until the polymer concentration was $1000 \mathrm{ppm}$. The mixing was carried out at 500 rpm for 90 seconds and the sample was carefully transferred to a $13 \mathrm{ml}$ container (inside diameter $\sim 2 \mathrm{~cm}$ ). The sample was allowed to settle for 24 hours and then scanned using the HRXMT. The sample was scanned in the middle portion of the sediment. This was done to avoid the sheared flocs that might be present in the top and bottom portions.

During the HRXMT scan, the sediment sample was well-confined and held by frictional forces in a cylindrically aligned container. The sample container as well as the sample inside the container had to be completely stable in order to get useful data. Any small movement will cause reconstruction failure and error. During the initial scans of sedimented kaolinite flocs at low polymer dosage and less mixing, the coalescence between the kaolinite flocs was affecting the stability of the sediment. The polymer dosage, mixing time and settling time were optimized to stabilize the sediment. After a few attempts, it was possible to get a sample that was stable during the 2 hours required for the tomographic scan.

\subsubsection{High resolution X-ray microtomography}

The high resolution XMT (MicroXCT- 400 from Xradia, Zeiss) at the University of Utah was used for this study. The basic layout is shown in Figure 2. More details about its principles and operation are available in the literature (Hsieh, 2012).

Experimental considerations are very important to achieve useful results. In this work, the same experimental conditions were used for all the samples scanned. Change in conditions would make the whole analysis pointless as the relationship established between scaled CT number and water content during calibration would no longer be valid. 

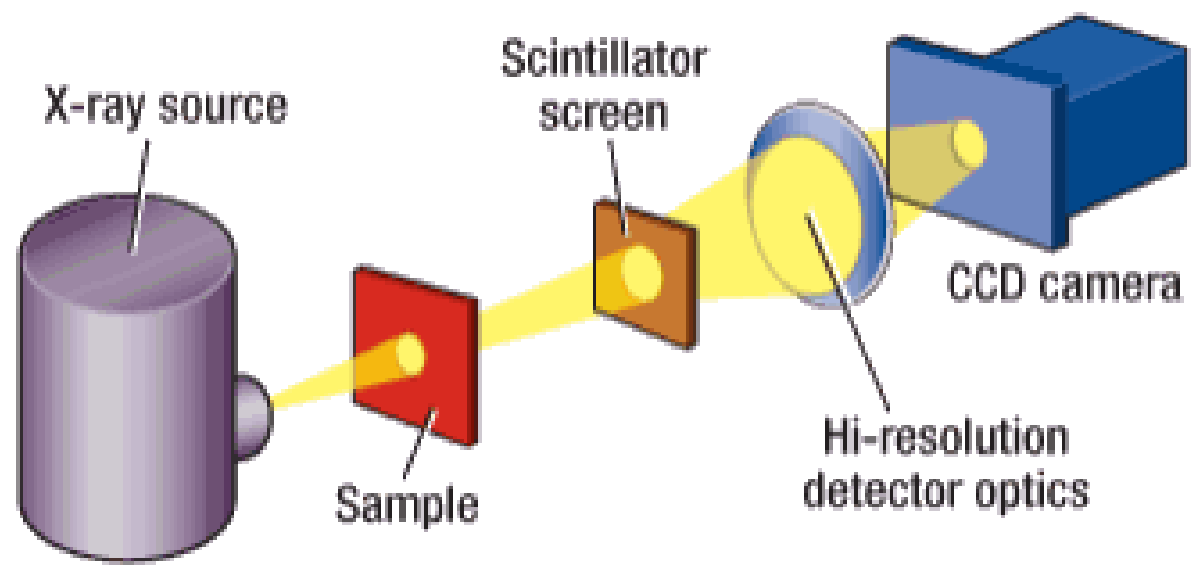

Figure 2: Layout of the HRXMT instrument, the Xradia/Zeiss Micro XCT-400 (Xradia, 2010).

The differences in attenuation coefficients between various phases of the sample determine the image quality of the HRXMT scan. The scan conditions for HRXMT analysis are determined by the differences in attenuation coefficients of the phases being scanned. After the scan, reconstruction of data is also a very important step in the HRXMT analysis. A detailed discussion on selection of HRXMT scan conditions and reconstruction considerations is available elsewhere (Hsieh, 2012). For this work, the CT scan conditions used are summarized in Table 1.

Table 1: Computational tomography (CT) conditions for the scan of flocculated kaolinite sediment.

\begin{tabular}{|l|l|}
\hline CT scan parameter & Value \\
\hline Accelerating voltage & $60 \mathrm{kV}$ \\
\hline Exposure time & $1.5 \mathrm{~s}$ \\
\hline Voxel resolution & 18.52 micron \\
\hline Filter & $150 \mathrm{micron}$ glass filter \\
\hline Field of View & $19 \mathrm{~mm}$ \\
\hline Source-sample distance & $60 \mathrm{~mm}$ \\
\hline Sample-detector distance & $120 \mathrm{~mm}$ \\
\hline Projection count & 1000 \\
\hline Lens & $0.5 X$ \\
\hline
\end{tabular}




\subsection{Floc microstructure}

\subsubsection{Sample preparation}

A kaolinite suspension (1\% w/v) was prepared using DI water obtained from a Milli-Q system. The resistivity of the water was greater than $18 \mathrm{M} \Omega$. The suspension was allowed to stir for 1 hour followed by 20 min sonication. The solution $\mathrm{pH}$ was 5.7. High mol. wt. 5\% anionic PAM polymer was added to the suspension at a dosage of $400 \mathrm{ppm}$ and stirring was continued for 60 second at $400 \mathrm{rpm}$. The flocculated suspension was allowed to settle for 1 hour .

For cryogenic sample preparation, a few flocs (about 2-3) were carefully placed on the conductive carbon tape glued to the metal stub used for SEM imaging. This was done using a $5 \mathrm{ml}$ plastic transfer pipette. About $2 \mathrm{ml}$ of water were sucked into the pipette and then very carefully 2-3 flocs from the sediment were sucked inside making sure the flocs did not break. The captured flocs were then carefully released onto the carbon tape. Extreme care was required in handling the flocs and placing them onto the carbon tape. Using tweezers, the stub was immersed horizontally in a container full of liquid nitrogen. The stub was taken out immediately and imaged at once before devitrification could take place. Using this method, the microfloc structure could be visualized, however, visualization of the polymer chains needed optimization with respect to a few conditions. After various attempts, it was found that adjustment of the sample amount on the stub, length of time in which the sample is dipped in liquid nitrogen, and imaging time were very crucial and determine the image quality for visualization of polymer chains.

\subsubsection{Scanning electron microscopy}

As mentioned in the introduction, Scanning Electron Microscopy (SEM) has been used widely for studying micro-structure of kaolinite clusters in the dry state. The SEM has a large magnification range, allowing examination of samples at magnifications well over 100,000. Besides magnification capabilities, SEM is capable of providing a large depth of field for images, which provides a three-dimensional perspective. Greater details about SEM principles and operation are available in the literature (Wells et al., 1974).

For this work we have used the Sigma 500 FESEM from Zeiss. The Sigma 500 FESEM has a powerful lens system, efficient detectors, and a vacuum system. More details about the equipment are available on the Zeiss website.

Cryo-SEM was used for visualization of kaolinite primary particles and polymer chains in the floc structure. Such examination was not easy due to the delicate nature of the floc structure. The sample was dipped in liquid $\mathrm{N}_{2}$ long enough to immobilize the water molecules but not so long that the whole sample was frozen and a thick frost layer formed. Since a cold stage was not used for imaging, the frosted sample started melting after a few seconds inside the sample chamber. This was not desired, as the melted water led to movement within the floc sample and sample features were not clear. However, if the floc sample was supercooled to immobilize the water and polymer chains, the polymer chains could be seen. It is doubtful, even with use of a cold stage, that visualization of polymer chains at such low polymer dosage would be possible, as frosting could break the delicate polymer chains present in the sample. However, visualization of polyacrylamide chains in DI water using the cryogenic method has been reported previously (Sui et al., 2015). For visualization of polyacrylamide polymer chains in water, a thin sample layer is 
recommended (Sui et al., 2015). Since, the amount of polymer in our sample was smaller and the concentration of kaolinite was much higher, we could not see the polymer chains when using a very small amount of the floc sample. Larger amounts of sample lead to contamination of the

lens. A balance was needed to get the desired results without any contamination. For all cryogenic floc samples a very low voltage was used (less than $2 \mathrm{kV}$ ), a higher voltage led to charging of the sample.

\section{Data analysis and image processing}

For the floc macrostructure and water content analysis of flocs, segmentation of the sediment bed was done so that individual flocs could be identified. Segmentation was achieved by following the principles used in the analysis of a multiphase packed particle bed developed by researchers at the University of Utah (Videla et al., 2006; Wang et al., 2015). Size analysis of all the segmented flocs and shape analysis for selected flocs was done. A calibration curve was plotted and used to determine the water content of the segmented flocs.

\subsection{Calibration curve}

The X-ray linear attenuation coefficient (CT number) is a function of material density, effective atomic number of each voxel, and the x-ray energy. The calibration curve for the water-kaolinite system was plotted using scaled CT numbers for water-kaolinite mixtures of known composition as shown in Figure 3. A linear relationship can be expected between water content and the scaled CT number (Lin et al., 2010). Using the fitted function, the water content of individual flocs was estimated based on the calculated scaled CT number for each floc in the sediment. 


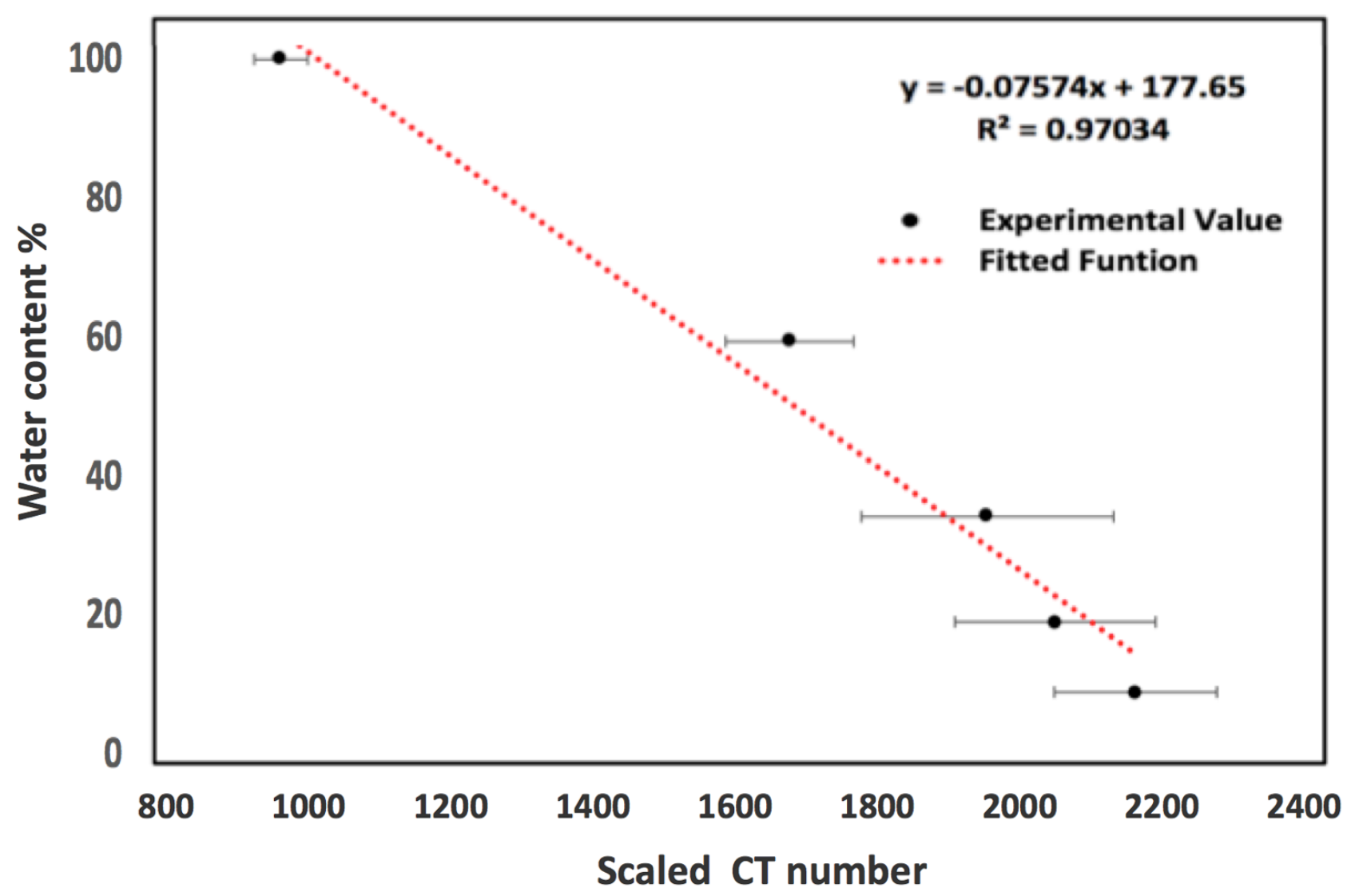

Figure 3: Calibration curve used for water content analysis of kaolinite flocs. The standard deviation for each data point and the line of best fit are displayed.

The calibration curve establishes a relationship between the scaled CT number and the water content. This equation can be used to find the water content of individual flocs by using the average CT number for each floc.

Water content \% (Y) = Intercept + Slope * Scaled CT number $(\mathrm{X})$

$Y=177.65-0.07574 * X$

Using this relationship, the intensity value (scaled CT number) was converted to the water content for each voxel and the intra-floc water content for each segmented floc was calculated.

\subsection{Segmentation of sedimented flocs}

The kaolinite floc sediment was scanned using the same HRXMT conditions as were used for calibration. The HRXMT data for the kaolinite sediment was processed as a stack of 370 2D images. Various segmentation tools such as trainable weka segmentation (Arganda-Carreras et al., 2015) and watershed segmentation (Beucher \& Meyer, 1993) were used for these images to identify individual flocs. 3D watershed segmentation has been developed at the University of Utah for segmentation of multiphase particle beds. 
The sedimented kaolinite flocs can be treated as a particle bed with two different phases, namely water and kaolinite. The water can be present in the water channels between flocs (interfloc water) or it can be present as entrapped water inside the flocs (intra-floc water) as seen in Figure 4. The interfloc water accounts for the complex channels found in the sediment and from which the permeability has been estimated by Lattice Boltzmann (LB) simulation in our research group at the University of Utah. The 3D watershed segmentation method was used with binary

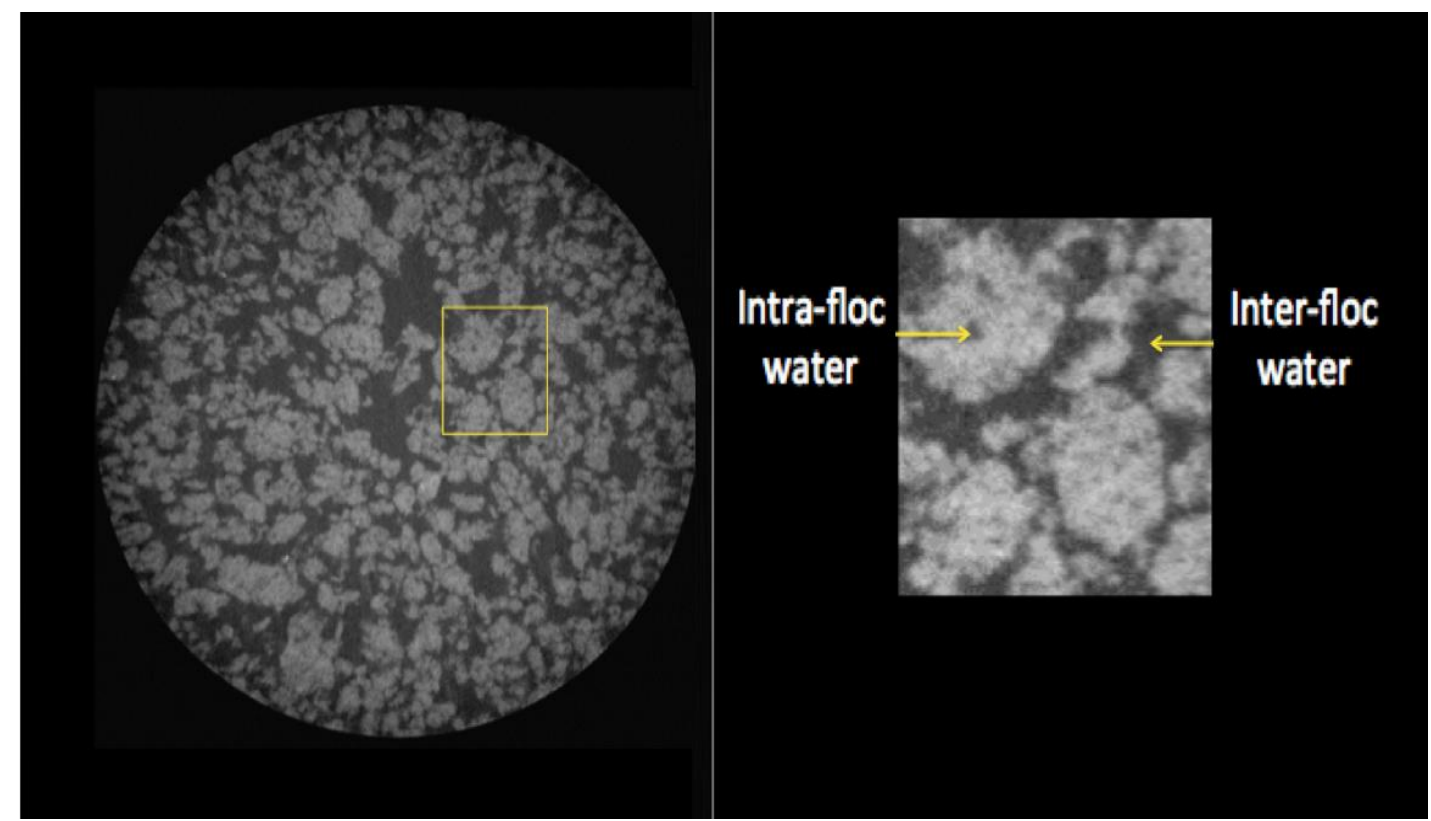

Figure 4: Illustration of intra-floc and inter-floc water in the original CT image. Quantification of both inter-floc and intra-floc water was done.

images for separation of flocs in contact. The process involves marker-controlled watershed segmentation and has been described in detail in the literature (Videla et al. 2006; Wang, 2016). It is evident that the segmented image contains isolated flocs with well-defined boundaries.

The kaolinite floc sediment was isolated into individual flocs. Each regional maxima in the segmented image was labelled with a unique number. This serves as an identification number to differentiate each floc from the rest of the flocs.

For size and water content analysis, all individual flocs with a total volume greater than 11 voxels were considered. The equivalent sphere diameter, $d$, for each floc was calculated using the total voxel volume as shown below:

Total voxel in a floc $*$ Volume of single voxel $=$ Volume of a floc

Volume of a floc $=\frac{\pi d^{3}}{6}$

Once the flocs were isolated, size, surface area, volume, aspect ratio, and sphericity can be calculated for the individual flocs using methods of shape analysis for 3D particles. The details about shape analysis for 3D particles using XMT can be found in the literature (Lin \& Miller, 2005). 


\section{Results and discussion}

\subsection{Floc water content and macrostructure}

A 3-dimensional view of the sediment with isolated flocs before and after segmentation is shown in Figure 5. By comparing the floc voxel volume with the total voxel volume, the composition of the sediment bed with respect to water was calculated. The sediment bed was found to contain $63 \%$ inter-floc water by volume. For this calculation, it was assumed that water channels contain $100 \%$ water with no solid particles. The total water content was found to be around $80 \%$ by volume (including both inter-floc and intra-floc water).
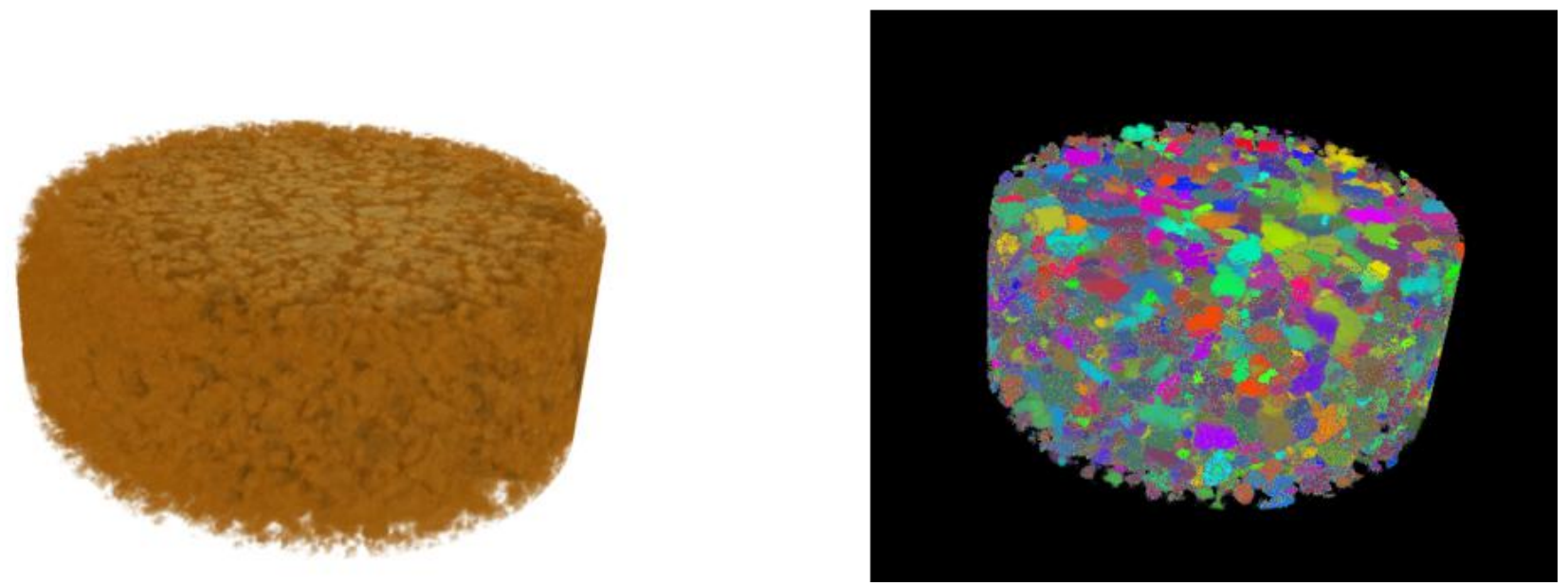

Figure 5: Unsegmented sediment bed (left); sediment bed after segmentation (right). Different colors represent different flocs in the segmented image.

For further analysis, individual flocs were isolated and analyzed for size and water content. Figure 6 shows selected isolated flocs along with their size and water content. 


\section{(1.45 mm, 36.5\%)}

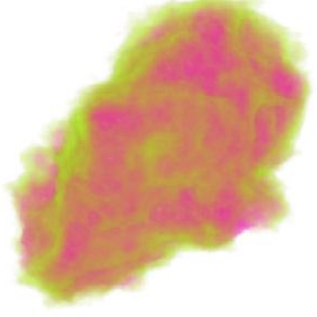

(1.24 mm, 53.5\%)

\section{(1.90 mm, 33.1\%)}

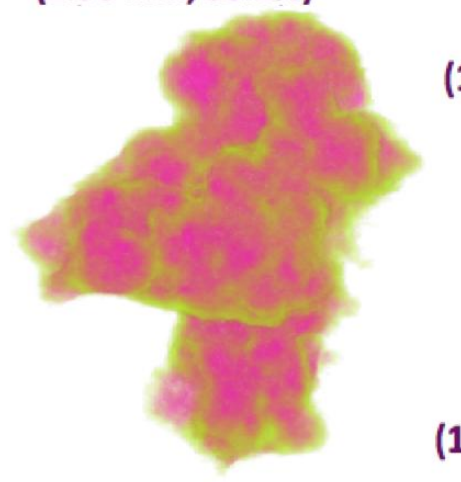

$(1.02 \mathrm{~mm}, 39.8 \%)$

$(1.04 \mathrm{~mm}, 50.1 \%)$

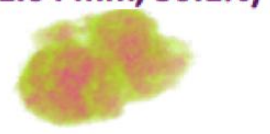

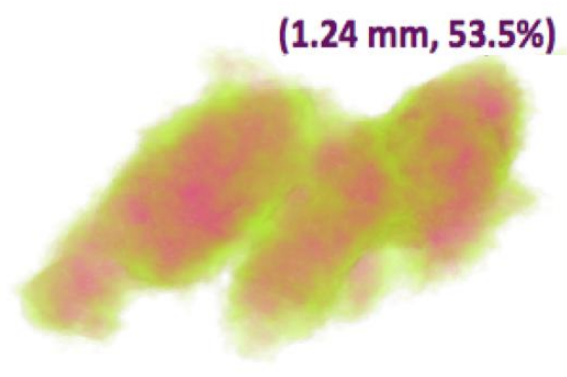

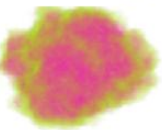

(1.20 mm, 38.7\%)

Fig 6: Selected individual flocs with floc size and water content respectively in parentheses. As the water content increases the color changes from pink to green.

The segmented bed was found to contain about 13 thousand flocs. Some of the very fine flocs were not considered for analysis. A threshold of 11 voxels was applied and flocs with a volume more than 11 voxels were considered for further analysis. Each of the flocs was analyzed for water content using a script based on Equation 1. The results suggest a normal distribution of water content for these flocs, with a mean water content of $53.9 \%$ by volume and standard deviation of $11.8 \%$. Most of the flocs had water content in the range of $50-59 \%$ (30.3\%), and about $98 \%$ of the flocs had water content in the range $30-80 \%$. The water content distribution for segmented flocs is shown in Figure 7. 


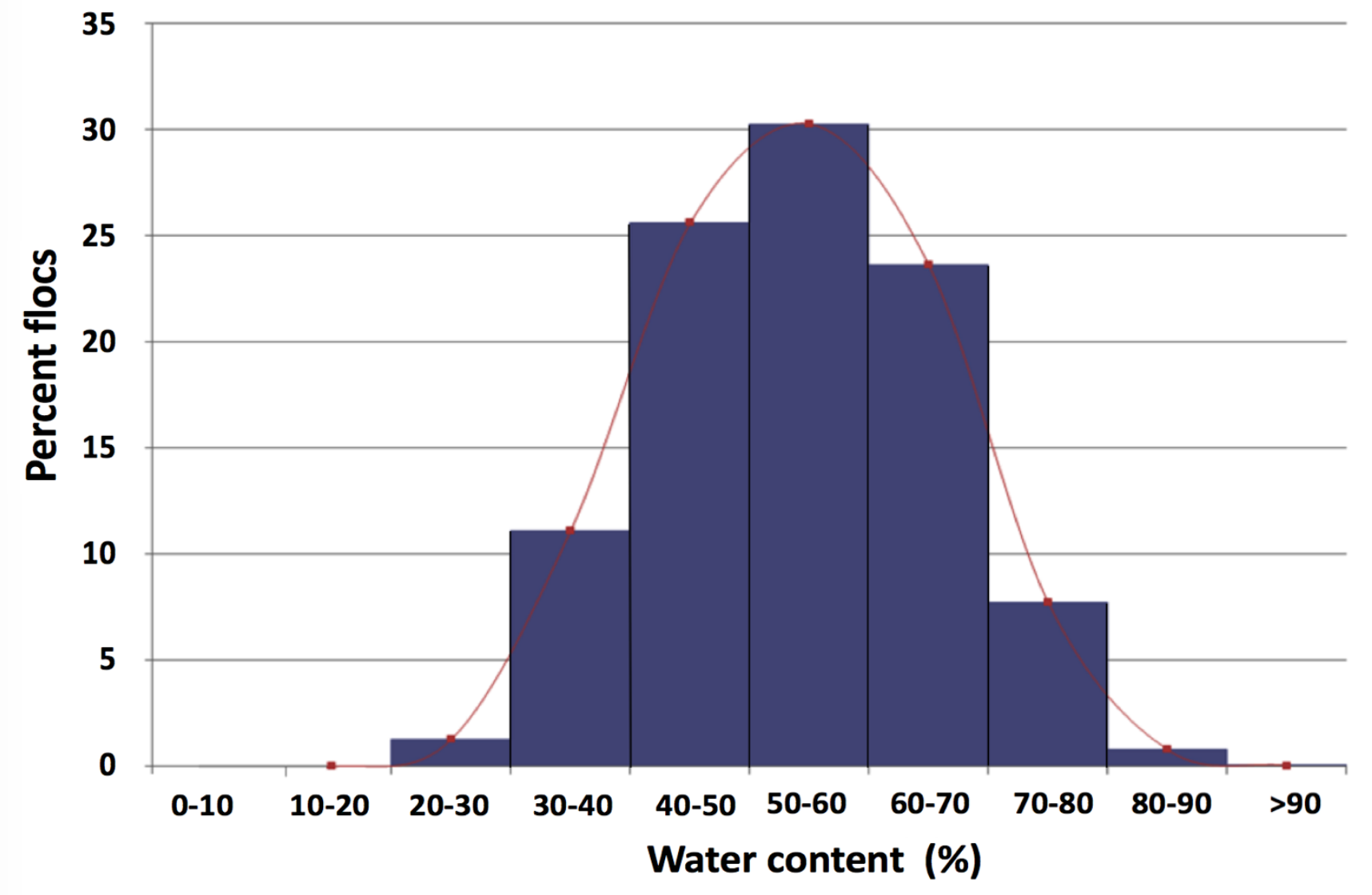

Figure 7: Water content distribution for kaolinite flocs, floc percent reported is by number. The sample was prepared at $\mathrm{pH}$ 5.8, 5\% solids, $1000 \mathrm{ppm}$ of high mol. wt. 5\% anionic PAM polymer and allowed to settle for 24 hours.

Size analysis of flocs was done using a script based on equation 2 . The equivalent sphere diameter was calculated and reported as floc size. The cumulative floc size distribution is shown in Figure 8. It should be noted that this distribution is based on voxel volume and not on voxel number. About $90 \%$ of the flocs were found to be less than $1.5 \mathrm{~mm}$ in size. Around $40 \%$ of the flocs had a size range of 0.5-0.85 $\mathrm{mm}$.

The flocs were divided into four size ranges and water content analysis for each size range was calculated. The results are provided as continuous scatter plots in Fig 9. Here we can see that the average water content of flocs increases with a decrease in floc size. Smaller flocs have more entrapped water than the larger flocs. Also, most of the flocs are in the size range 0.12-0.85 mm. 


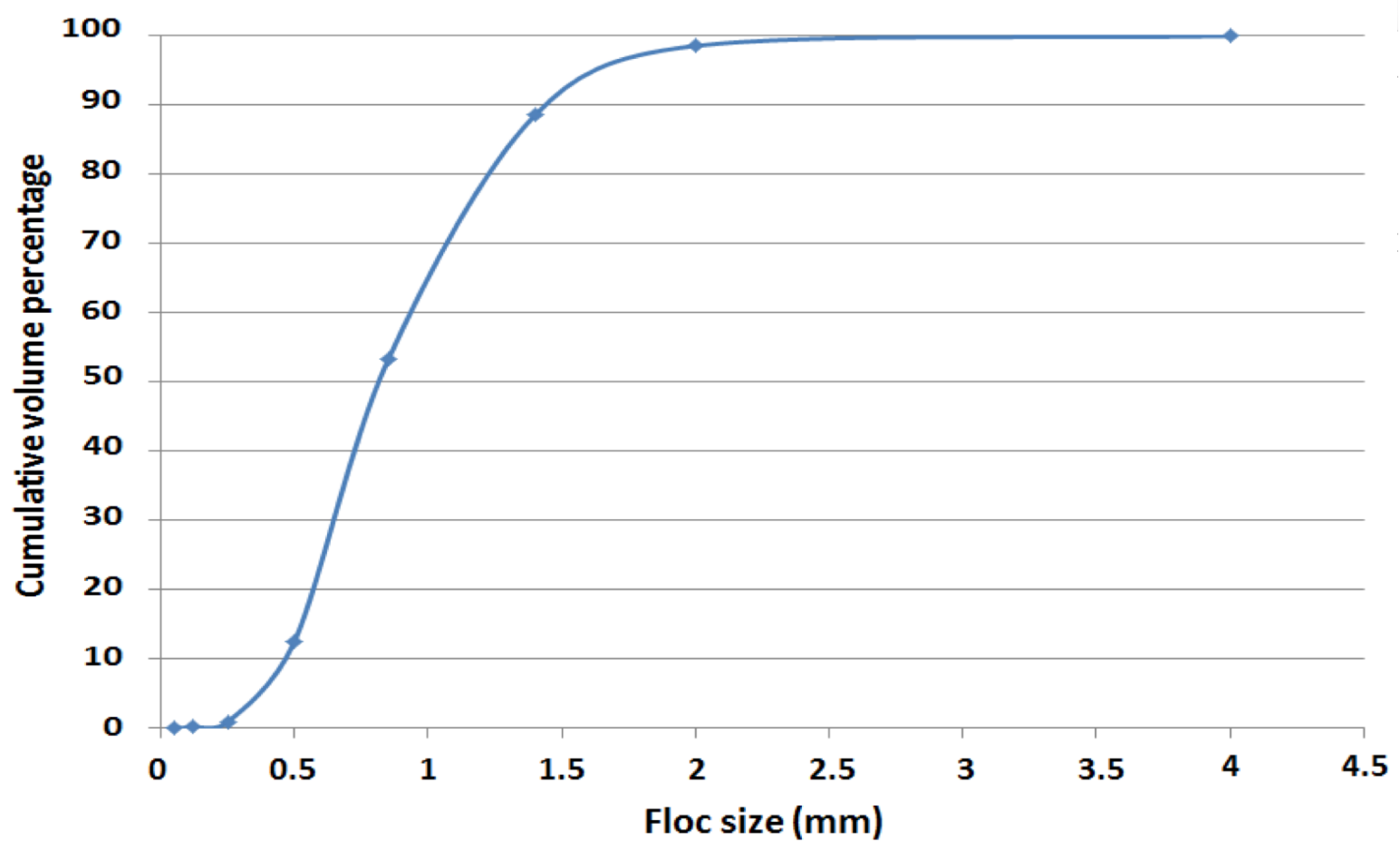

Figure 8: Floc size distribution of kaolinite flocs. Equivalent sphere diameter is reported for each floc size. The sample was prepared at pH 5.8, 5\% solids, $1000 \mathrm{ppm}$ of high mol. wt. 5\% anionic PAM polymer and allowed to settle for 24 hours.

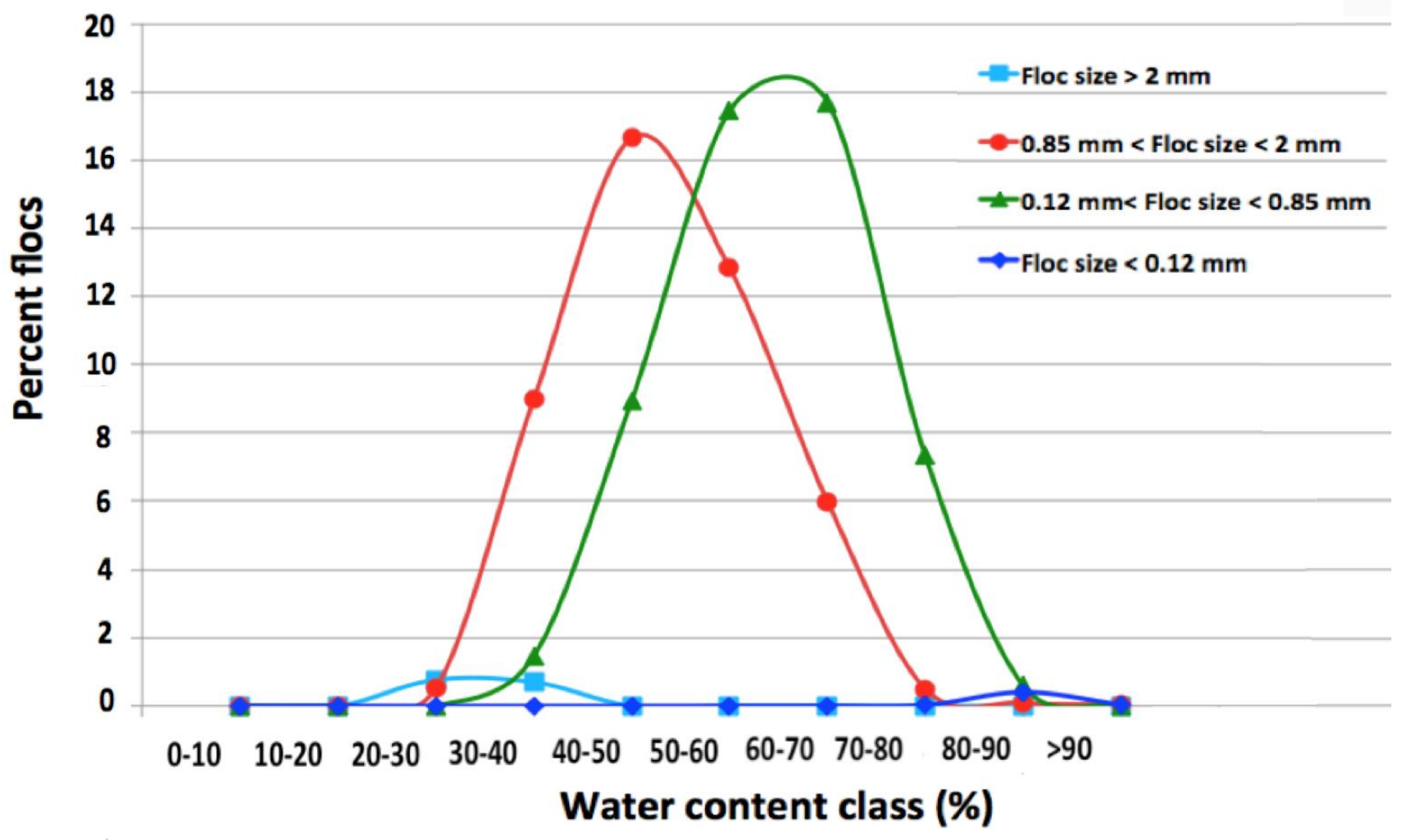

Figure 9: Water content distribution of flocs in various floc size ranges, the percent of floc is by number. The sample was prepared at $\mathrm{pH} 5.8,5 \%$ solids, $1000 \mathrm{ppm}$ of high mol. wt.

$5 \%$ anionic PAM polymer and allowed to settle for 24 hours. 
The isolation of individual flocs makes it possible to analyze various features of these flocs. The floc shape can be characterized by calculating the floc surface area, volume, aspect ratio, and sphericity. These features of 3D particles can be calculated using the method of shape analysis for 3D particles developed by Lin \& Miller (2005). Shape analysis was done for 10 flocs and is reported along with water content and size in Table 2.

The shape analysis was not done for the entire population of 13 thousand flocs and the results for 10 individual flocs cannot be extrapolated to include the entire floc population. The flocs that were analyzed were found to be highly irregular with sphericity $\sim 0.1$. Due to the highly irregular shape of these flocs, there were complications in finding the surface area of some flocs, especially for the ones with high water content. A single floc was sometimes identified as a combination of flocs by the program. Manual analysis of each individual floc was done and is recommended in the case of such irregular and porous particles to avoid errors.

Table 2: Shape analysis of selected flocs in the sediment bed.

\begin{tabular}{|c|c|c|c|c|c|c|c|c|}
\hline \multirow[t]{2}{*}{ Floc No. } & \multirow[t]{2}{*}{ Size $(\mathrm{mm})$} & \multirow[t]{2}{*}{ Water Content (\%) } & \multirow[t]{2}{*}{ Volume $(\mathrm{mm})^{3}$} & \multirow[t]{2}{*}{ Surface Area $(\mathrm{mm})^{2}$} & \multicolumn{3}{|c|}{ Aspect Ratio } & \multirow[t]{2}{*}{ Sphericity } \\
\hline & & & & & Length & Width & Height & \\
\hline 1 & 1.50 & 62.40 & 4.13 & 25.57 & 1.38 & 1.21 & 1 & 0.061 \\
\hline 2 & 1.70 & 33.00 & 3.39 & 24.07 & 1.79 & 1.19 & 1 & 0.101 \\
\hline 3 & 2.30 & 28.20 & 2.41 & 31.90 & 1.64 & 1.10 & 1 & 0.108 \\
\hline 4 & 0.54 & 60.00 & 1.67 & 13.71 & 3.18 & 2.08 & 1 & 0.109 \\
\hline 5 & 1.43 & 43.00 & 1.17 & 10.08 & 2.13 & 1.95 & 1 & 0.110 \\
\hline 6 & 1.00 & 54.70 & 0.85 & 07.46 & 2.29 & 1.67 & 1 & 0.113 \\
\hline 7 & 0.81 & 56.00 & 0.25 & 03.79 & 1.95 & 1.65 & 1 & 0.113 \\
\hline 8 & 1.26 & 31.00 & 0.09 & 01.97 & 1.95 & 1.55 & 1 & 0.118 \\
\hline 9 & 1.20 & 38.70 & 0.31 & 03.89 & 1.53 & 1.10 & 1 & 0.128 \\
\hline 10 & 0.79 & 43.40 & 0.00 & 00.08 & 1.73 & 1.37 & 1 & 0.139 \\
\hline
\end{tabular}

The HRXMT procedure developed in this work has allowed not only the determination of floc structure but also the water content of individual flocs. The procedure developed can be extended to water content and size distribution analysis of flocs formed from industrial tailings under different conditions. 


\subsection{Floc microstructure}

The orientation and organization of primary particles within the kaolinite microflocs was imaged using cryo-SEM. Edge-to-face, and face-to-face interactions were revealed as shown in Figure 10. With higher magnification, face-to-face interaction between finer and coarser primary particles was found (Figure 11).

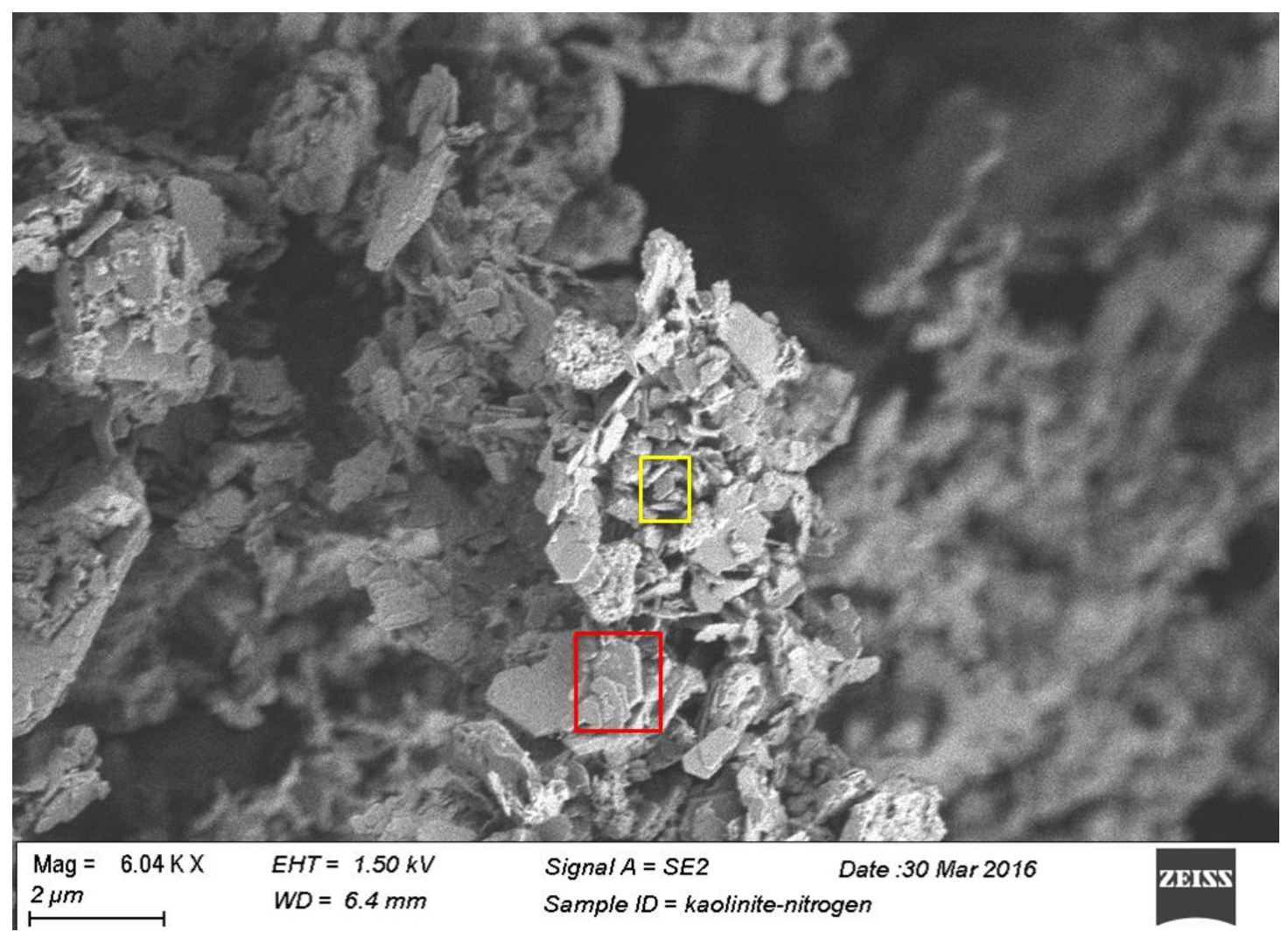

Figure 10: Cryo-SEM image of kaolinite microfloc at pH 5.7. The primary particles show edge-face interaction (highlighted in yellow) and face-face interaction (highlighted in red). 


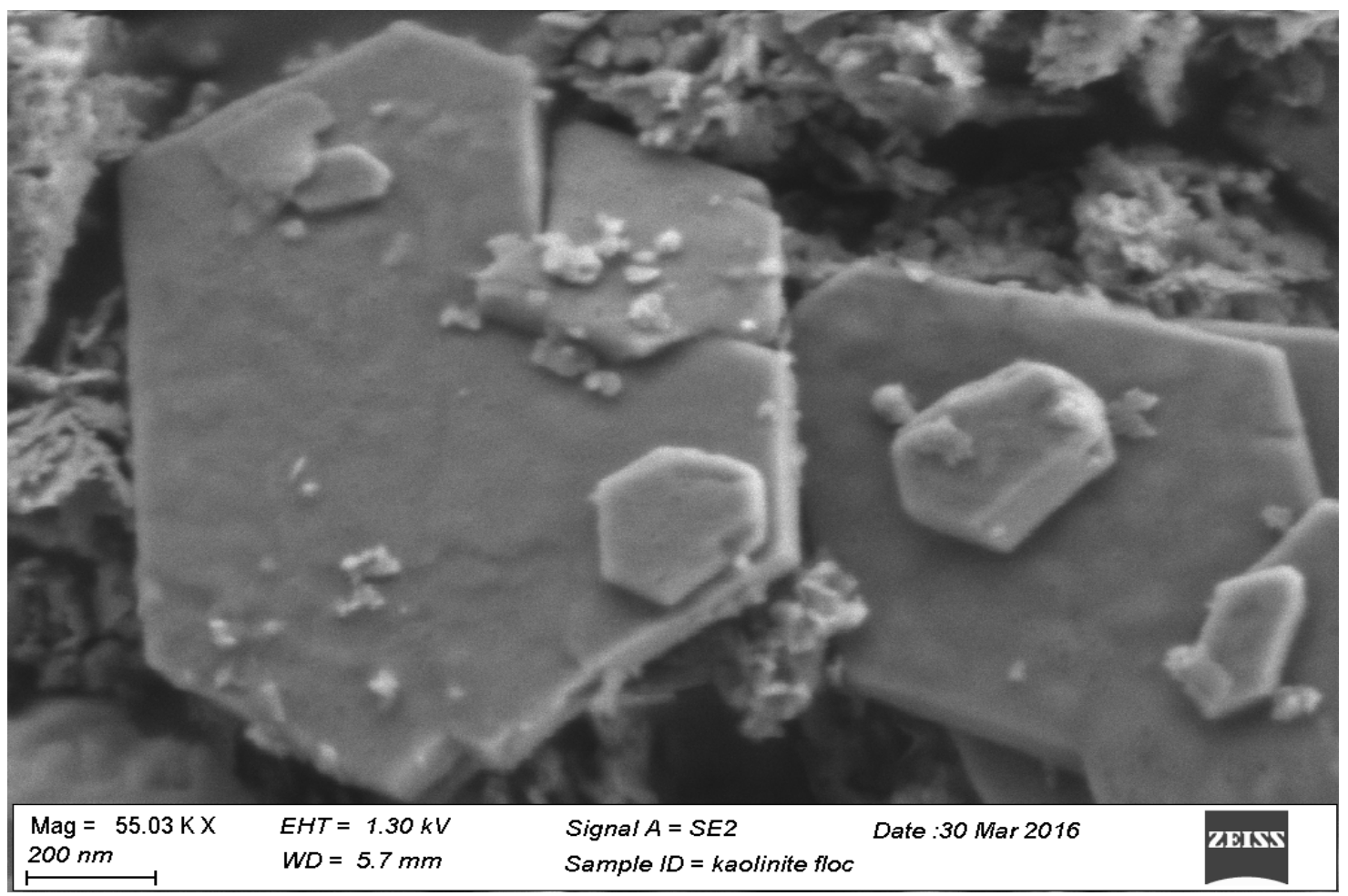

Figure 11: High magnification cryo-SEM image of kaolinite primary particles within the microfloc. Here we can see the face-face interaction between the primary particles.

The microscale examination of kaolinite flocs by the cryogenic method reveals that microflocs from $0.5 \mu \mathrm{m}$ to about $10 \mu \mathrm{m}$ in size are interconnected by polymer chains (Figure 12). The polymer chains form close ended web like stuctures, bridging various microflocs to one another. These polymer chains can vary in dimensions as can been seen from these images; the thickness of the PAM chains vary from a few $\mathrm{nm}$ to about $80 \mathrm{~nm}$. These polymer chains seem to be elastic in nature, and capable of changing dimensions based on the force exterted from different ends. The smaller microflocs could be attached to the ends of a single polymer chain but the larger microflocs were found to be intertwined between many chains. It appears that more than one attachment point between the larger flocs and the polymer chain is necessary for structural stability of the floc. It was also noticed that the chain length between two consecutive microflocs varies a lot, from almost continuous microflocs with no apparent polymer link to polymer chain links of about $5 \mu \mathrm{m}$. It appears that breakage of these delicate chain structures occurs under shear and hence the well known sensitivity of floc stability to turbulence level. For different polymers, there would be a critical chain length beyond which breakage occurs thus restricting the size to which the floc grows. 


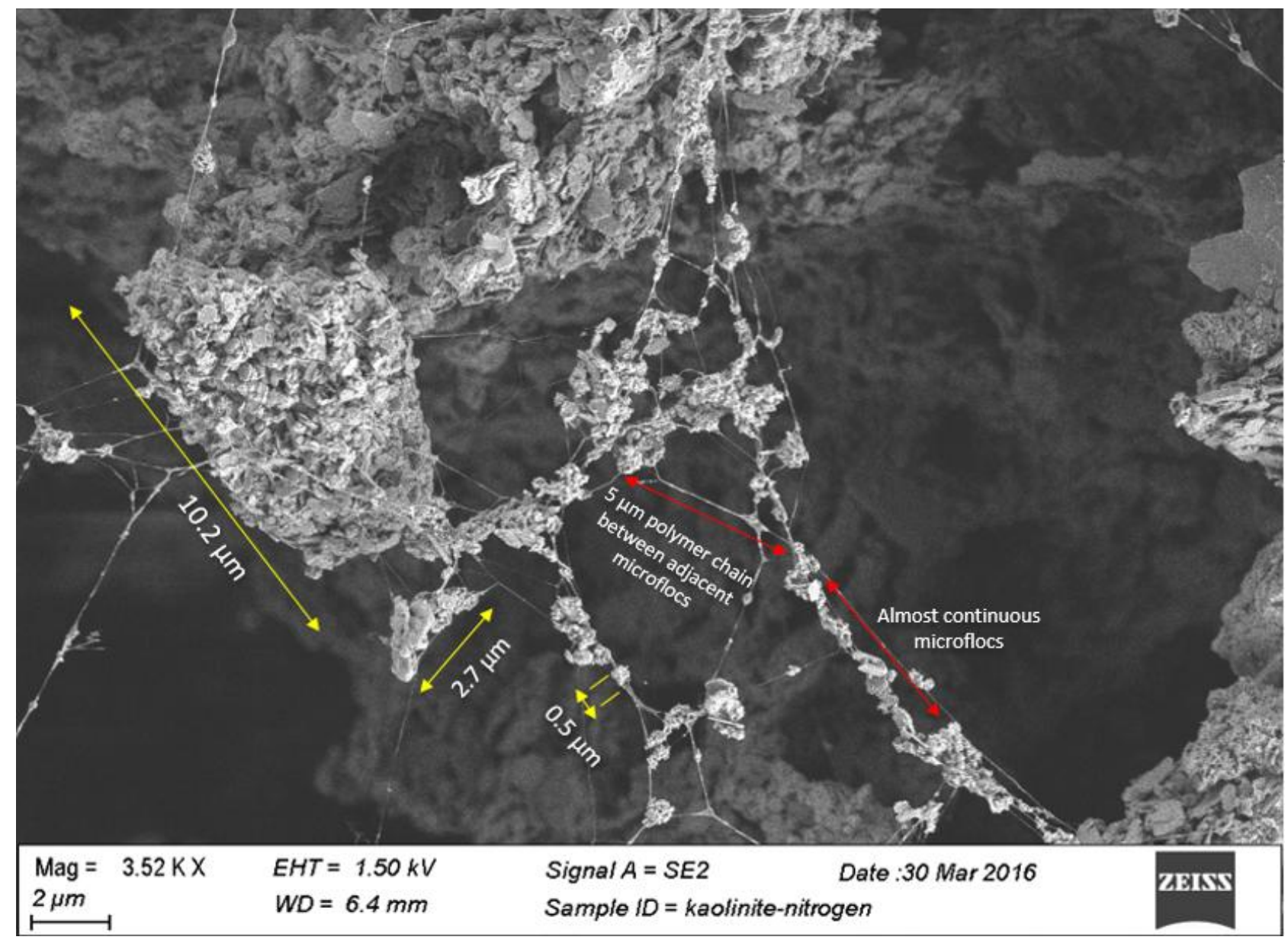

Figure 12: Microstructure of kaolinite floc as revealed by cryo-SEM. The microflocs containing primary kaolinite nanoparticles vary in size from $0.5 \mu \mathrm{m}$ to $10 \mu \mathrm{m}$ (highlighted in yellow). The microflocs could be almost continuous or have a significant length of polymer chain in between adjacent microflocs

(highlighted in red).

Here, it should be noted that the variation in polymer chain dimension could be due to stacking of fine polymer chains giving rise to thicker chains or due to the presence of undissolved polymer chains. The polyacrylamide chain contains both positive and negative sites in the hydrated state. Depending on the relative orientaion of these groups in the polymer chain, there is a chance of aggregation due to electrostatic forces. It is also possible that the loss in water due to cryo freezing and sublimation leads to collapse of the fine poymer network and results in thicker polymer chains.

Due to the limits of 2 dimensional visualization, it is difficult to say at which surface of the kaolinite particle these polymer chains attach. It appears that the polymer bridges are formed by attachment to both face and edge surfaces. It is possible that the anionic PAM polymer chain attaches to the alumina face (positively charged at pH 5.7) by hydrogen bonding with the edge surface. Upon increasing the magnification, we can see a couple of polymer chain-edge surface attachements with some clarity in Figure 13. 
The multiscale 3D analysis of polymer induced kaolinite flocs is summarized in Figure 14 which considers the floc sediment bed at the $\mathrm{cm}$ level, individual flocs at the $\mathrm{mm}$ level, microflocs at the $\mu \mathrm{m}$ level, and polymers and primary particles at the $\mathrm{nm}$ level. Note that the floc sediment contains $\sim 13,000$ flocs, individual flocs may contain a million primary kaolinite nanoparticles, and that polymer fibers as small as $10 \mathrm{~nm}$ are revealed.

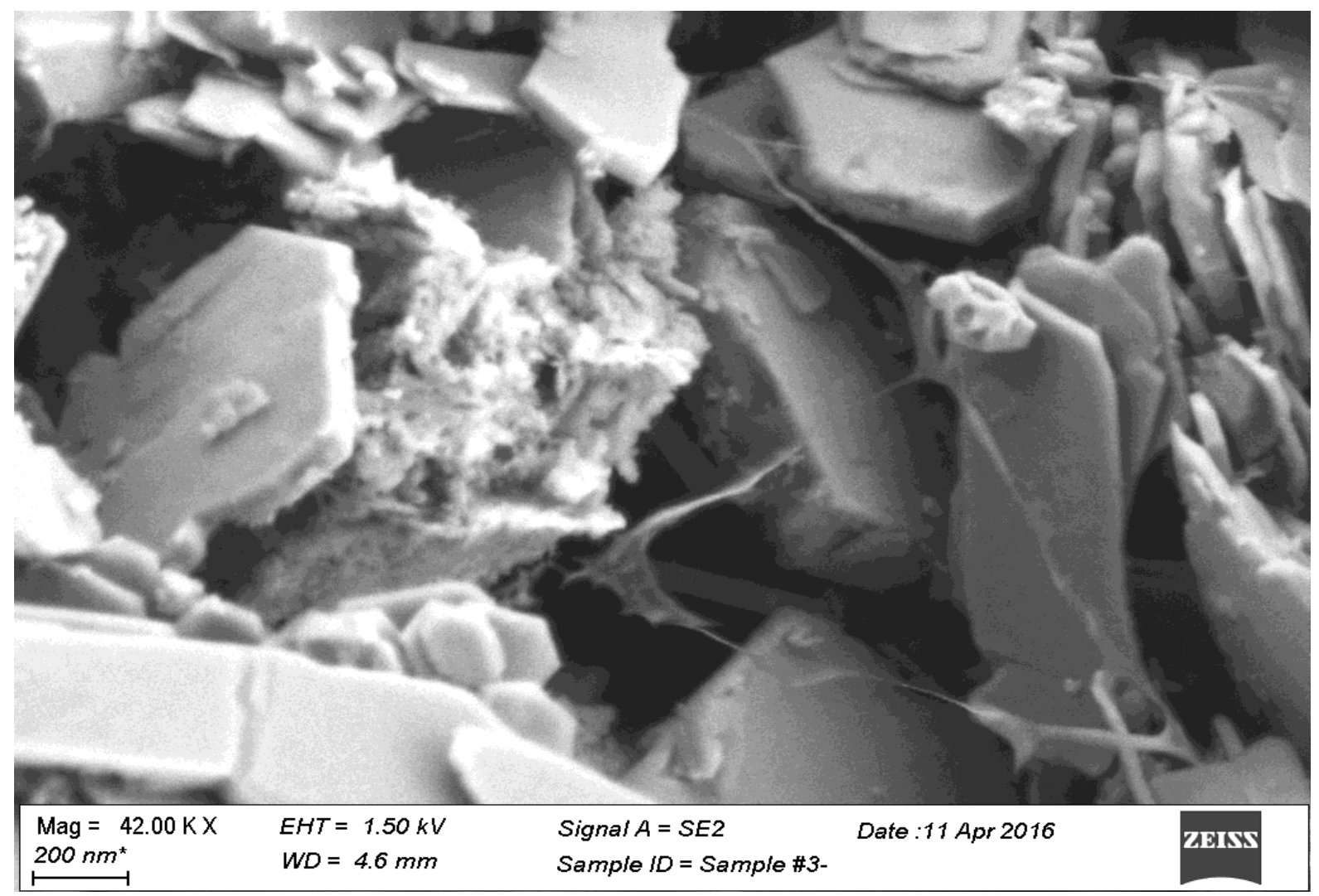

Figure 13: Cryo-SEM microstructure of kaolinite floc at higher magnification. Interaction between kaolinite edge surfaces - polymer chains are evident. 

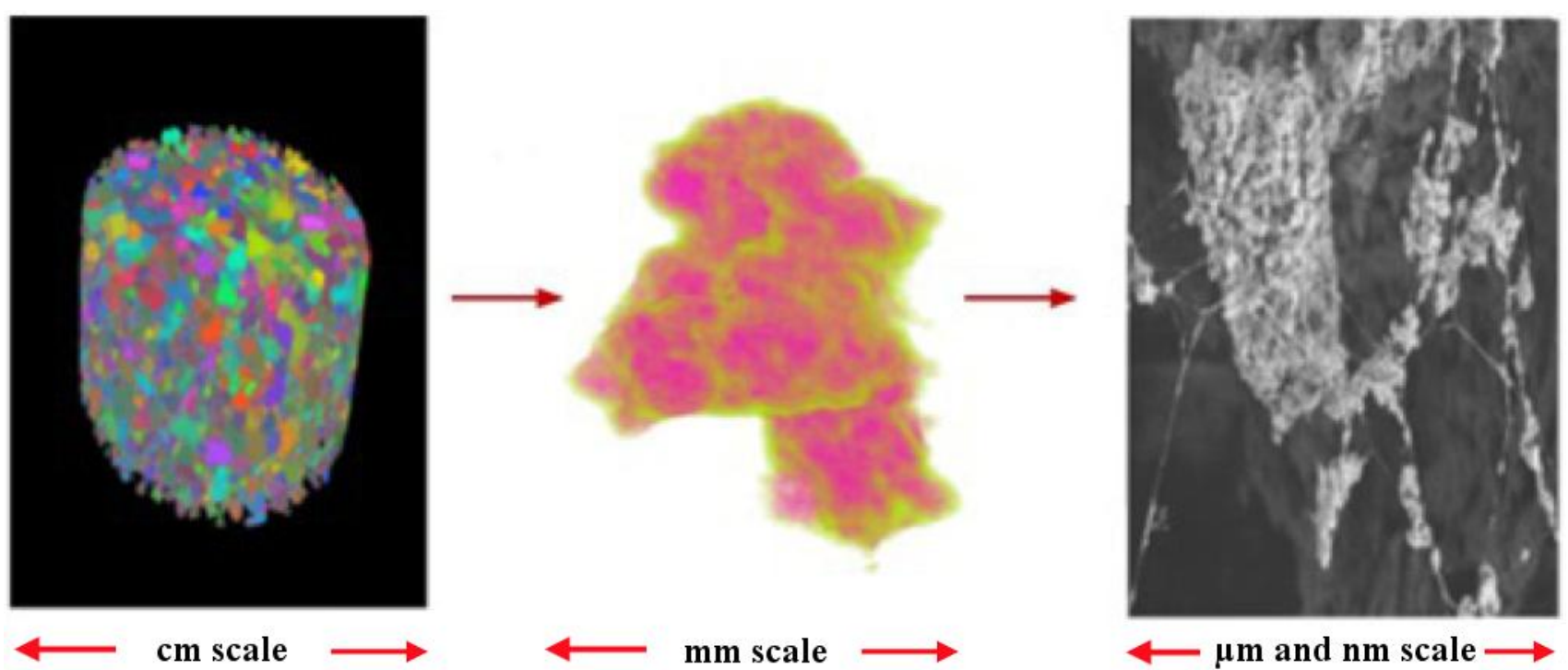

Figure 14: Multiscale analysis of kaolinite flocs. The sediment bed (on left) was segmented and individual flocs were isolated. One individual floc of about two $\mathrm{mm}$ in size is shown in the middle. The water content analysis of individual flocs was done. As the water content increases, the color changes from pink to green. The individual floc was further investigated for its microsctructure by using SEM and cryo sample preparation to indentify kaolinite primary particles and polymer chains (on right).

\section{Conclusions}

A multi-scale investigation of polymer induced kaolinite flocs has been reported for the first time using HRXMT and cryo-SEM procedures to determine not only floc structure, but also the water content of individual kaolinite flocs, as well as the microstructure of primary kaolinite nanoparticles (Figure 14). The procedure developed can be extended to water content and size distribution analysis of flocs formed from industrial tailings at different conditions. This would enable us to study the effect of different parameters on the water entrapped in individual flocs as well as on the size distribution of the floc population. Both size and water content of flocs are crucial in determining the settling and self-weight consolidation of flocs.

The use of cryo-SEM for visualization of floc microstructure and polymer chain organization reveals the stabilization of primary kaolinite nanoparticles in the web formed by polymer chains. The morphology of the polymer chains as well as the interaction between the primary kaolinite nanoparticles and polymer chains is a key aspect of understanding floc growth and stability.

\section{Acknowledgements}

This research was funded by the Division of Chemical Sciences, Geosciences, and Biosciences, Office of Basic Energy Sciences of the U.S. Department of Energy (DOE), Grant No. DE-FG0393ER14315. Thanks are extended to Zeiss, Sympatec, Hychem, and Pocock Industrial for their help in this research. Recognition is also given to Yan Wang for her assistance with imaging and analysis, and Dorrie Spurlock, who helped to prepare the manuscript for publication. 


\section{References:}

I. Arganda-Carreras, A. Cardona, V. Kaynig, J. Schindelin, Trainable Weka Segmentation (Fiji) (2015). http://fiji.sc/Trainable_Weka_segmentation.

B.J. Berne, R. Pecora, Dynamic Light Scattering: With Applications to Chemistry, Biology, and Physics. Wiley-Interscience, New York, NY, USA (2000).

S. Beucher, F. Meyer, The morphological approach to segmentation: The watershed transformation, in Mathematical Morphology in Image Processing (Ed: E.R. Dougherty). Marcel Dekker, New York, NY, USA (1993), 433-467.

R.K. Chakraborti, J.F. Atkinson, J.E.V. Benschoten, Characterization of alum floc by image analysis. Environ. Sci. Technol. 34 (2000) 3969-3976.

R.J. Chalaturnyk, J.D. Scott, B. Ozum, Management of oil sands tailings. Pet. Sci. Technol. 20 (2002) 1025.

J. Du, R.A. Pushkarova, R.S.C. Smart, A cryo-SEM study of aggregate and floc structure changes during clay settling and raking processes. Int. J. Miner. Process. 93 (2009) 66-72.

A. Fan, P. Somasundaran, N.J. Turro, Proton nuclear magnetic resonance study of water in flocs. Langmuir 15 (1999) 4922-4926.

D. Garcia, C.L. Lin, J.D. Miller, Quantitative analysis of grain boundary fracture in the breakage of single multiphase particles using X-ray microtomography procedures. Miner. Eng. 22 (2009) 236-243.

V. Gupta, J.D. Miller, Surface force measurements at the basal planes of ordered kaolinite particles. J. Colloid \& Interface Sci. 344 (2) (2010) 362-371.

H.C.M. Hendricks, The effect of $\mathrm{pH}$ and the solids composition on the settling and self-weight consolidation of mud. MS Thesis, Technical University of Delft. Delft, Netherlands (2016).

C.H. Hsieh, Procedure and analysis of mineral samples using high resolution X-ray micro tomography. MS Thesis, University of Utah, Salt Lake City, UT, USA (2012).

Q. Jiang, B.E. Logan, Fractal dimensions of aggregates determined from steady state size distributions. Environ. Sci. Technol. 25 (1991) 2031- 2038.

C.P. Johnson, X. Li, B.E. Logan, Settling velocities of fractal aggregates. Environ. Sci. Technol. 30 (1996) 1911-1918.

T.T. Kie, Investigations of the rheological properties of clays. PhD Dissertation, Technical University of Delft. Delft, Netherlands (1954).

S. Kim, A.M. Palomino, Polyacrylamide-treated kaolin: A fabric study. Applied Clay Sci. 45 (2009) 270-279. 
D.F. Lawler, Removing particles in water and wastewater. Environ. Sci. Technol. 20 (1986) 856-861.

X. Li, B.E. Logan, Collision frequencies between fractal aggregates and small particles in a turbulently sheared fluid. Environ Sci. Technol. 31 (1997) 1237-1242.

A. Limaye, Drishti: A volume exploration and presentation tool. Proc. SPIE 8506, Developments in X-Ray Tomography VIII, 85060X (2012).

C.L. Lin, J.D. Miller, 3D characterization and analysis of particle shape using X-ray microtomography (XMT). Powder Technol. 154 (2005) 61-69.

C.L. Lin, J.D. Miller, Advances in X-ray computed tomography (CT) for improved coal washability analysis. R.Q. Honaker (Ed.). International Coal Preparation Congress, SME, CO, USA (2010).

C.L. Lin, A.R. Videla, Q. Yu, J.D. Miller, Characterization and analysis of porous, brittle solid structures by X-ray micro computed tomography. J. of Metal. 62 (2010) 86-89.

J. Liu, C.L. Lin, J.D. Miller, Simulation of cluster formation from kaolinite suspensions. Int. J. Miner. Process. 145 (2015) 38-47.

J. Liu, L. Sandaklie-Nikolova, X. Wang, J.D. Miller, Surface force measurements at kaolinite edge surfaces using Atomic Force Microscopy. J. Colloid \& Interface Sci. 420 (2014) 35-40.

M. McAuliffe, F. Lalonde, D. McGarry, W. Gandler, K. Csaky, B. Trus, Medical image processing, analysis and visualization in clinical research. Proc. of the 14th IEEE Symposium on Computer-Based Medical Systems (2001) 381-386.

F. Mietta, Evolution of the floc size distribution of cohesive sediments. PhD Dissertation, Technical University of Delft. Delft, Netherlands (2010).

P. Mpofu, M.J. Addai, J. Ralston, Influence of hydrolyzable metal ions on the interfacial chemistry, particle interactions, and dewatering behavior of kaolinite dispersions. J. Colloid Interface Sci. 261 (2003) 349-59.

C.R. O'Melia, Coagulation and sedimentation in lakes, reservoirs and water treatment plants. Water Sci. Technol. 37 (1998) 129-135.

J. Schindelin, I. Arganda-Carreras, E. Frise, et al., Fiji: an open-source platform for biologicalimage analysis. Nature Methods 9 (2012) 676-682.

X. Sui, B. Wang, H. Wu, J. Dong, S. Feng, Morphology of polyacrylamide in solution: effect of water quality on viscosity. Polymers for Adv. Technol. 26 (2015) 1326-1330.

H.Van Olphen, An Introduction to clay colloid chemistry: for clay technologists, geologists, and soil scientists. Wiley, New York, NY, USA (1977). 
A. Videla, C.L. Lin, J.D. Miller, Watershed functions applied to a 3D image segmentation problem for the analysis of packed particle beds. Part. Part. Syst. Char. 23 (2006) 237-245.

Y. Wang, Image processing techniques for 3D analysis of multiphase multisize packed particle beds using X-ray tomography. PhD Dissertation, University of Utah, Salt Lake City, UT, USA (2016).

Y. Wang, C.L. Lin, J.D. Miller, Improved 3D image segmentation for X-ray tomographic analysis of packed particle beds. Miner. Eng., 83 (2015) 185-191.

O.C. Wells, A. Boyde, E. Lifshin, A. Rezanowich, Scanning Electron Microscopy. McGraw-Hills, New York, NY, USA (1974).

M.R. Wiesner, Kinetics of aggregate formation in rapid mixtures. Water Res. 26 (1992) 379387.

J.C. Winterwerp, W.G.M. van Kesteren, Introduction to the physics of cohesive sediment in the marine environment. Developments in Sedimentology 56. Elsevier, Oxford, UK (2004).

Xradia, MicroXCT-200 and MicroXCT-400 User's Guide. Xradia, (2010), pp. 87, 155, 175, and 283-284.

M.S. Zbik, R.S.C. Smart, G.E. Morris, Kaolinite flocculation structure. J. Colloid Interface Sci. 328 (2008) 73-80.

P. Zhang, M. Bogan, Recovery of phosphate from Florida beneficiation slimes I. Re-identifying the problem. Miner. Eng. 8 (1995) 523-534. 


\section{Graphical abstract}

Sedimented Kaolinite Flocs

( 13,000 individual flocs)
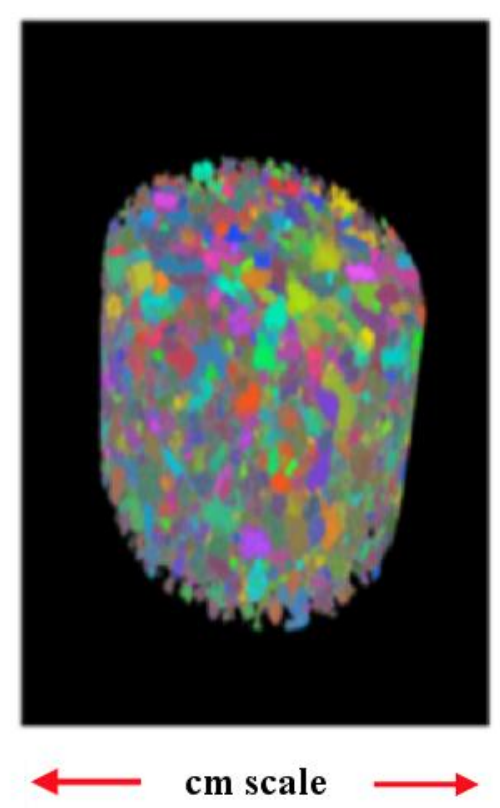

Individual Kaolinite Floc

Size $1.2 \mathrm{~mm}$, Water Content $31 \%$

(over a million primary particles)

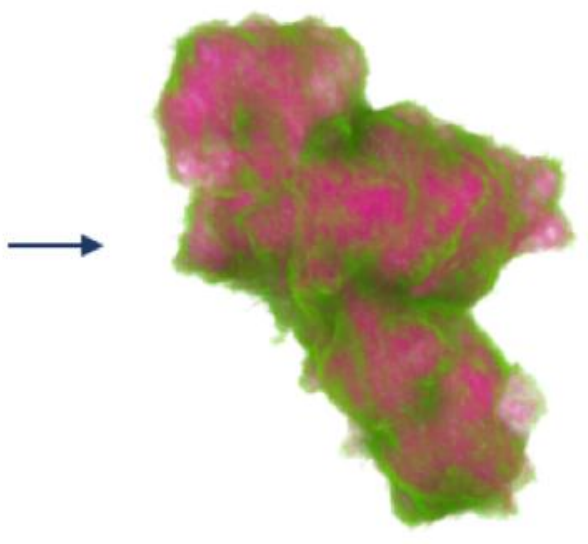

mm scale
Kaolinite Microfloc Stabilized by Polymer Chains (primary particles visible)

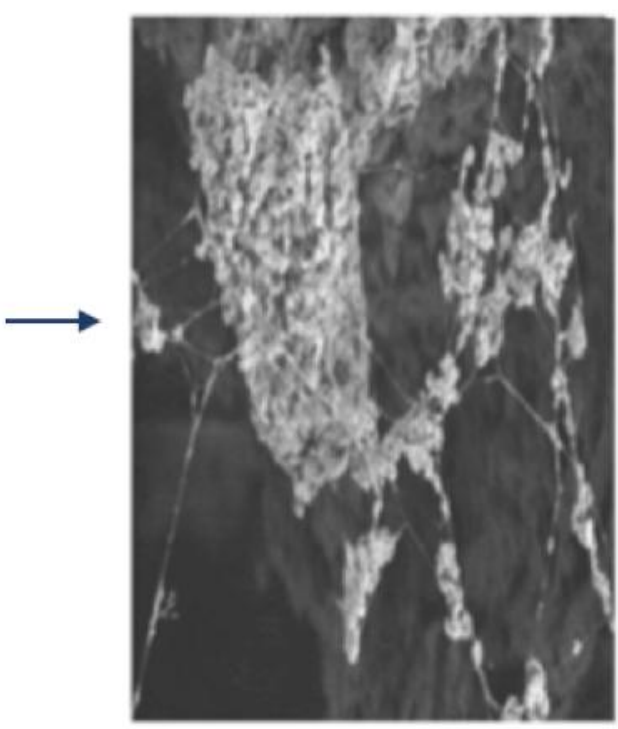

$\mu \mathrm{m}$ and $\mathrm{nm}$ scale $\longrightarrow$

HRXMT analysis of sedimented kaolinite flocs (left) revealed the size, shape and water content distribution of individual flocs (middle). The individual flocs were further investigated for microstructure by cryo-SEM to indentify kaolinite primary particles and polymer flocculant (right) 